\title{
Flow and Heat Transfer Analysis of a Nanofluid Along a Vertical Flat Plate with Non-Uniform Heating Using Fem: Effect of Nanoparticle Diameter
}

\author{
Puneet Rana and R. Bhargava
}

\begin{abstract}
Steady two dimensional natural convection laminar boundary layer flow of an incompressible $\mathrm{Al}_{2} \mathrm{O}_{3}$-water nanofluid along a vertical flat plate with streamwise sinusoidal surface temperature has been investigated numerically. The resulting non-linear governing equations have been solved, using an extensively validated, Galerkin Finite Element Method (FEM) for spherical shaped nanoparticles with volume fraction upto $4 \%$, with associated boundary conditions. Dynamic based models have been implemented, for calculating the effective thermal conductivity and dynamic viscosity of nanofluid. Heat transfer enhancement is observed and highlighted due to the presence of nanoparticles. The effects of the various other parameters are discussed to achieve better control on the rate of heat transfer.
\end{abstract}

Index Terms-FEM, Natural convection, Nanofluids, Sinusoidal temperature, Vertical flat plate.

\section{INTRODUCTION}

The heat transfer enhancement is one of the most important technical aims for engineering systems due to its wide applications in electronics cooling systems, next-generation solar film collectors, heat exchangers technology, and various thermal systems. Choi [1] was the first person to introduce the word "nanofluids". Nanofluids, i.e., dilute suspensions of nanoparticles, which are typically made of metals $(\mathrm{Al}, \mathrm{Cu})$ [2], metal oxides $\left(\mathrm{Al}_{2} \mathrm{O}_{3}, \mathrm{SiO}_{2}, \mathrm{TiO}_{2}\right)$ nanoparticles or nonmetals (Graphite, Carbon) nanotubes in liquids, may exhibit quite different thermal properties than the pure carrier fluids. The base fluid is usually a conductive fluid, such as water, ethylene glycol, oils, Bio-fluids, Polymer solutions etc.

The classical conductivity theory of solid-fluid suspensions used for large-size particle suspensions could not explain as to why low concentrations of nanoparticles can enhance the thermal conductivity of base fluids notably larger than the model predication. Wang et al. [3] first proposed new mechanisms behind enhanced thermal transport in nanofluids, such as particle motion and eletrokinetic effects. Xuan and Li [4] recommended several possible mechanisms for enhanced thermal conductivity of nanofluids.

Later, it was found that the effective thermal conductivity

Manuscript received October 10, 2011; revised November 20, 2011.

P. Rana would like to thank Council of Scientific and Industrial Research (CSIR), Government of India, for its financial support through the award of a research grant.

P. Rana and R. Bhargava are with the Department of Mathematics, Indian Institute of Technology Roorkee, 247667, INDIA (e-mail: puneetranaiitr@gmail.com; rbharfma@iitr.ernet.in). of nanofluids depends not only on the nanostructures of the suspensions but also on the dynamics of nanoparticles in liquids at high temperature. Koo and Kleinstreuer [5] stated that the effective thermal conductivity is composed of the particle's conventional static part and a Brownian motion part.

It is well known that power law surface temperature distributions give rise to self similar boundary layer flows [6, 7]. However, Rees [8] and Roy and Hossain [9] proposed another form of surface temperature variation, namely, sinusoidal variations about a mean temperature which is held above the ambient temperature of the fluid. This type of surface temperature may be considered to define the periodic array of heaters behind or within the wall. Recently, Saha et al. [10] studied the sinusoidal temperature variation with time on the inclined walls of the attic space and Molla et al. [11] discussed the radiation effect on natural convection flow along a vertical plate with streamwise surface temperature.

In the present paper, we study the Natural convection of $\mathrm{Al}_{2} \mathrm{O}_{3}$-water nanofluid along the vertical plate with sinusoidal heating, using the models introduced by Li [12]. The effects of various parameters have been studied.

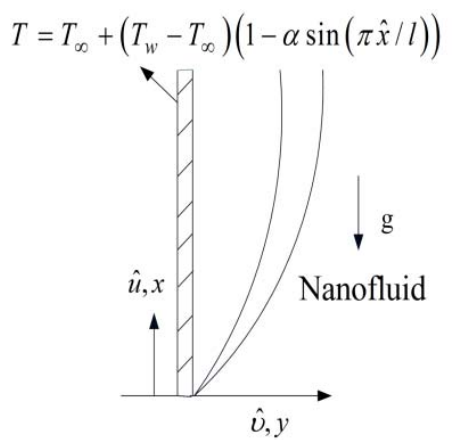

Fig. 1. Physical Model and Co-ordinate system.

\section{MATHEMATICAL ANALYSIS}

A steady two-dimensional laminar free convective flow from a non-isothermal semi-infinite vertical flat plate, which is immersed in an incompressible $\mathrm{Al}_{2} \mathrm{O}_{3}$-water nanofluid, is considered. It is assumed that the heated surface temperature of the plate is maintained at the steady temperature.

$$
T=T_{\infty}+\left(T_{w}-T_{\infty}\right)(1-\alpha \sin (\pi \hat{x} / l))
$$

where $T_{\infty}$ is the ambient temperature, $T_{w}$ is the mean surface temperature with $T_{w}>T_{\infty}, \alpha$ is the relative amplitude of the 
surface temperature variations and $2 l$ is the wavelength of the variations. The base fluid and the nanoparticles are in thermal equilibrium and no slip occurs between them. The coordinates system and the flow configuration are shown in Fig. 1.

The boundary layer and Boussinesq approximations are assumed to be valid. The thermo physical properties of the nanofluid are taken from [13]. The basic steady conservation of mass, momentum and thermal energy equations for nanofluids can be written in Cartesian coordinates $\mathrm{x}$ and $\mathrm{y}$ as,

$$
\begin{gathered}
\frac{\partial \hat{u}}{\partial \hat{x}}+\frac{\partial \hat{v}}{\partial \hat{y}}=0 \\
\hat{u} \frac{\partial \hat{u}}{\partial \hat{x}}+\hat{v} \frac{\partial \hat{u}}{\partial \hat{y}}=\frac{1}{\rho_{n f}}\left[\mu_{n f} \frac{\partial^{2} \hat{u}}{\partial \hat{y}^{2}}+(\rho \beta)_{n f} g\left(T-T_{\infty}\right)\right] \\
\hat{u} \frac{\partial T}{\partial \hat{x}}+\hat{v} \frac{\partial T}{\partial \hat{y}}=\frac{1}{\left(\rho C_{p}\right)_{n f}}\left[k_{n f} \frac{\partial^{2} T}{\partial \hat{y}^{2}}\right]
\end{gathered}
$$

where, $(\hat{u}, \hat{v})$ are the velocity components along the $(\hat{x}, \hat{y})$ axes, $\rho_{n f}$ is the nanofluid density, $\mu_{n f}$ is the effective dynamic viscosity of the nanofluid. $T$ is the temperature of the nanofluid, $\beta_{n f}$ is the thermal expansion of the nanofluid, $g$ is the acceleration due to gravity.

The boundary conditions are:

$$
\begin{aligned}
& \hat{u}=\hat{v}=0, T=T_{\infty}+\Delta T(1-\alpha \sin (\pi \hat{x} / l)) \text { at } y=0, \\
& \hat{u} \rightarrow 0, T \rightarrow T_{\infty} \text { as } y \rightarrow \infty
\end{aligned}
$$

To obtain the non-dimensional governing equations let us introduce the following non-dimensional variables

$$
\begin{gathered}
x=\frac{\hat{x}}{l}, y=G r^{1 / 4}\left(\frac{\hat{y}}{l}\right), u=\frac{l}{v_{f}} G r^{-1 / 2} \hat{u}, v=\frac{l}{v_{f}} G r^{-1 / 4} \hat{v}, \\
\theta=\frac{T-T_{\infty}}{T_{w}-T_{\infty}}, G r=\frac{g \beta\left(T_{w}-T_{\infty}\right) l^{3}}{v_{f}}
\end{gathered}
$$

where, Gr is Grashof number. $v_{f}=\mu_{f} / \rho_{f}$ is the reference kinematic viscosity, $\theta$ is the non-dimensional temperature function. Substituting the variables into Eqs (2)-(5) lead to the following non-dimensional equations, we get

$$
\frac{\partial u}{\partial x}+\frac{\partial v}{\partial y}=0
$$

$$
u \frac{\partial u}{\partial x}+v \frac{\partial u}{\partial y}=\frac{1}{\left(1-\phi+\phi \frac{\rho_{s}}{\rho_{f}}\right)}\left[\frac{\mu_{n f}}{\mu_{f}} \frac{\partial^{2} u}{\partial y^{2}}+\left[1-\phi+\phi \frac{(\rho \beta)_{s}}{(\rho \beta)_{f}}\right] \theta\right]
$$

$u \frac{\partial T}{\partial x}+v \frac{\partial T}{\partial y}=\frac{1}{\left(1-\phi+\phi\left(\rho C_{p}\right)_{s} /\left(\rho C_{p}\right)_{f}\right)} \frac{1}{\operatorname{Pr}} \frac{k_{n f}}{k_{f}} \frac{\partial^{2} T}{\partial y^{2}}$

and the corresponding boundary conditions are

$$
\begin{gathered}
u=v=0, \theta=1+\alpha \sin (\pi x) \text { at } y=0, \\
u \rightarrow 0, \theta \rightarrow 0 \quad \text { as } y \rightarrow \infty
\end{gathered}
$$

where Pr is Prandtl number, $\phi$ is the nanoparticle volume fraction. The thermophysical properties of the nanofluid, namely the density, heat capacity and volumetric expansion coefficient, have been calculated from nanoparticle and base fluid properties at the ambient temperature and are as follows [14]:

$$
\begin{aligned}
& \rho_{n f}=(1-\phi) \rho_{f}+\phi \rho_{s} \\
& (\rho \beta)_{n f}=(1-\phi)(\rho \beta)_{f}+\phi(\rho \beta)_{s} \\
& \left(\rho C_{p}\right)_{n f}=(1-\phi)\left(\rho C_{p}\right)_{f}+\phi\left(\rho C_{p}\right)_{s}
\end{aligned}
$$

The effective thermal conductivity of the nanofluid is determined based on the models presented in [12].

\section{NUMERICAL SOLUTION}

The finite element method is a powerful technique for solving differential equations whether ordinary or partial as well as integral equations. The basic concept is that the whole domain is divided into various smaller elements of finite dimensions called "Finite Elements". It is the most versatile numerical technique in modern engineering analysis and has been employed to study diverse problems in heat transfer, fluid mechanics, chemical processing, rigid body dynamics, solid mechanics, electrical systems and many other fields. The steps involved in the finite element analysis are as follows:

1. Finite-element discretization

2. Generation of the element equations

3. Assembly of Element Equations

4. Imposition of boundary conditions

5. Solution of assembled equations

The assembled equations so obtained can be solved by any of the numerical technique viz. Gauss elimination method, LU Decomposition method, etc.

Before we employ the FEM, we need to reduce the aforementioned equations to a convenient set of equations. To do that, we first introduce the following transformations over the govering equation:

$$
\begin{aligned}
& \psi=x^{3 / 4} f(x, \eta), \quad \eta=x^{-1 / 4} y, \quad \theta=\theta(x, \eta) \\
& u=\partial \psi / \partial y, \quad v=-\partial \psi / \partial x
\end{aligned}
$$

Substituting (12) into Eqs. (7)-(10) and after some algebraic manipulations, the transformed equations take the following form 


$$
\begin{gathered}
\frac{1}{\left(1-\phi+\phi \rho_{s} / \rho_{s}\right)}\left\{\frac{\mu_{n f}}{\mu_{f}} f^{\prime \prime \prime}+\left[1-\phi+\phi \frac{(\rho \beta)_{s}}{(\rho \beta)_{f}}\right] \theta\right\} \\
+\frac{3}{4} f f^{\prime \prime}-\frac{1}{2} f^{\prime 2}=x\left(f^{\prime} \frac{\partial f^{\prime}}{\partial x}-f^{\prime \prime} \frac{\partial f}{\partial x}\right), \\
\frac{1}{\left(1-\phi+\phi\left(\rho C_{p}\right)_{s} /\left(\rho C_{p}\right)_{f}\right)}\left[\frac{1}{\operatorname{Pr}}\left(\frac{k_{n f}}{k_{f}}\right) \theta^{\prime \prime}\right] \\
+\frac{3}{4} f \theta^{\prime}=x\left(f^{\prime} \frac{\partial f^{\prime}}{\partial x}-f^{\prime \prime} \frac{\partial f}{\partial x}\right),
\end{gathered}
$$

along with the boundary conditions

$$
\begin{aligned}
& f(x, 0)=f^{\prime}(x, 0)=0, \quad \theta(x, 0)=1+\alpha \sin (\pi x), \\
& f^{\prime}(x, \infty) \rightarrow 0, \theta(x, \infty) \rightarrow 0 .
\end{aligned}
$$

The physical quatities of principle interest are the shearing stress and the rate of heat transfer in terms in terms of the skin-friction coefficient $C_{f}$ and the Nusselt number $N u$ which can be written as

$$
\begin{aligned}
& C_{f}=C_{f} G r_{x}^{1 / 4} / 2=\left(\mu_{n f} / \mu_{f}\right) f^{\prime \prime}(x, 0), \\
& N u=N u G r_{x}^{-1 / 4}=-\left(k_{n f} / k_{f}\right) \theta^{\prime}(x, 0) .
\end{aligned}
$$

Finally, the average Nusselt number is determined from:

$$
N u_{\text {avg }}=\left(\frac{1}{p}\right) \int_{0}^{p} N u(X) d X
$$

Here $p$ is the length of the plate .The average Nusselt number in Eq. (17) has been evaluated numerically.

\section{RESUlTS AND Discussion}

To provide a physical insight into the flow problem, comprehensive numerical computations are conducted for various values of the parameters that describe the flow characteristics and the results are illustrated graphically. The effect of solid volume fraction is investigated in the range of $0-4 \%$. Also, it has been observed that if the concentration exceeds the maximum level of $8 \%$, sedimentation takes place.

Selected computations are presented in figures 1 to 7 . The ranges of the parameters are considered: $300 \leq t \leq 325$, $0.0 \leq \alpha \leq 1.0,0 \leq \phi \leq 0.04,20 \mathrm{~nm} \leq d \leq 100 \mathrm{~nm}$. Default parameters: $\mathrm{Al}_{2} \mathrm{O}_{3}$-water nanofluids, $t=310 \mathrm{~K}, \alpha=0.2, d=$ $30 \mathrm{~nm}$ (diameter of nanoparticles).

In order to verify the accuracy of the numerical solutions, the validity of the present numerical code has been compared with Molla et al. [11] for a limiting case $(\operatorname{Pr}=0.7, \phi=0.0)$ as shown in fig. 2. The three dimensional profiles for both velocity and temperature at each point on the plate have also been shown in figs. $3(\mathrm{a}-\mathrm{b})$ keeping $\mathrm{d}=20 \mathrm{~nm}$. Moreover, an extensive mesh testing procedure was conducted to ensure a grid- independence solution of given boundary value problem.
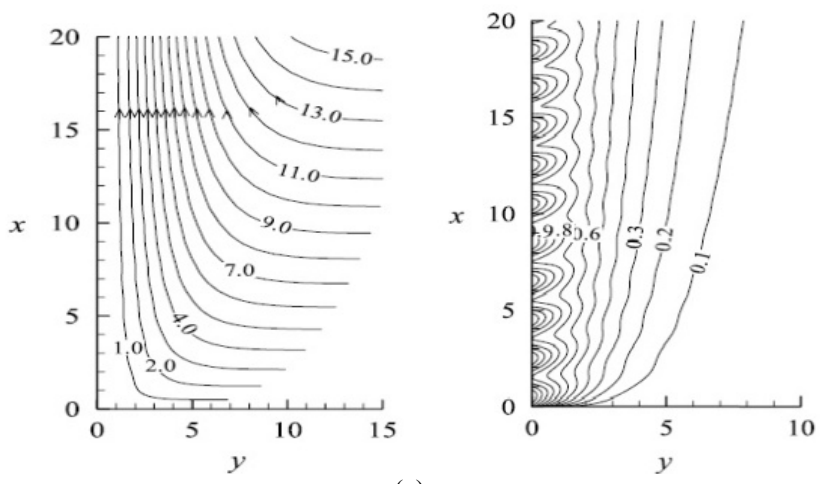

(a)
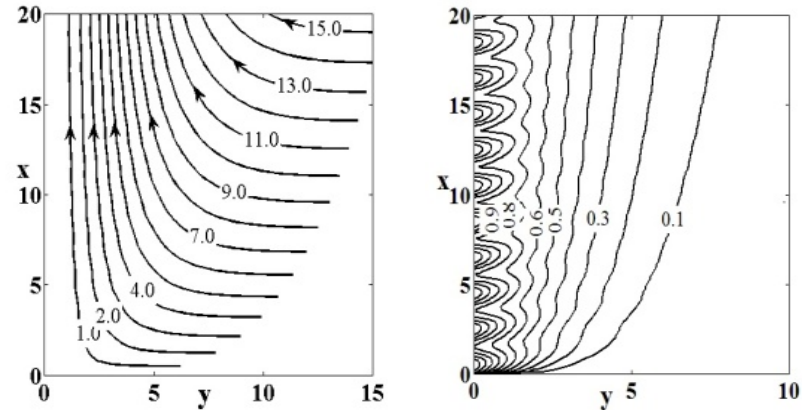

(b)

Fig. 2. (a) Streamlines and isotherms by Molla et al. [11] (b) Present FEM results.

Different combinations of meshes for both pure water and $\mathrm{Al}_{2} \mathrm{O}_{3}$-water were also explored as shown in Table 1 . In the case of $\mathrm{Al}_{2} \mathrm{O}_{3}$-water, average Nusselt number of different nanoparticle diameter $(\mathrm{d}=20 \mathrm{~nm}$ and $100 \mathrm{~nm})$ has been taken into consideration. Another grid independence study was performed for $\mathrm{Al}_{2} \mathrm{O}_{3}$-water nanofluid by varying the nanoparticle volume concentration. It has been found that a grid size of $181 \times 101$ grid points ensures the grid independent solution. The results presented here are independent of step size up to four decimal places.

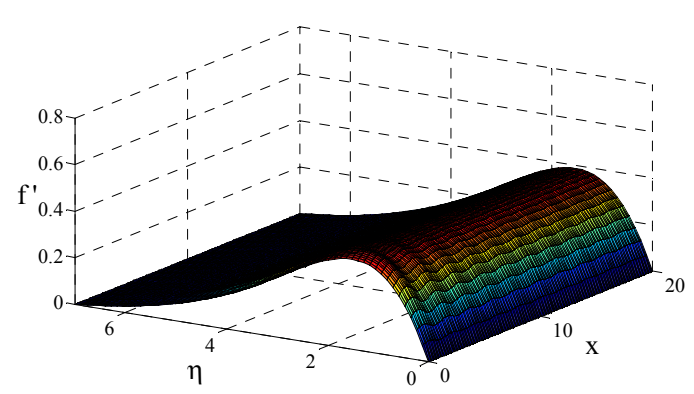

(a)

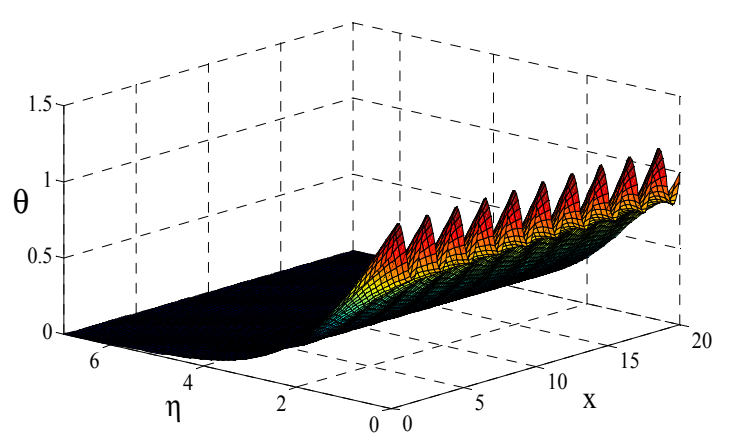

(b)

Fig. 3. 3D plots of (a) dimensionless velocity (b) dimensionless temperature for nanofluids while $\phi=0.04, \mathrm{t}=320 \mathrm{~K}, \mathrm{~d}=20 \mathrm{~nm}$. 


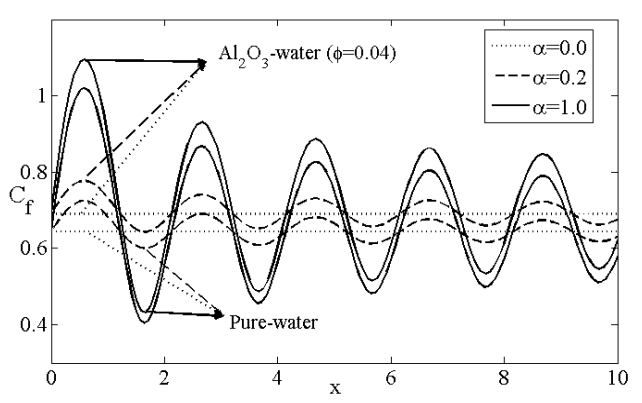

(a)

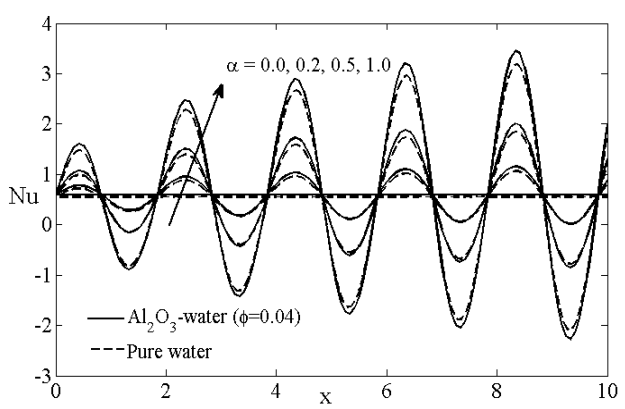

(b)

Fig. 4. (a) Skin friction coefficient and (b) Nusselt number of both Pure-water and nanofluids while $\phi=0.04, \mathrm{t}=320 \mathrm{~K}$.

Fig. 4 shows the skin friction and Nusselt number comparison of $\mathrm{Al}_{2} \mathrm{O}_{3}$-water nanofluids and Pure water with different values of temperature wave amplitude on the plate for $\mathrm{t}=320 \mathrm{~K}$. It is clear from the figures that both the skin friction coefficient and the Nusselt number are uniform all over the plate if the amplitude is zero. However, with the increase of the amplitude of the heating effect both parameters also increase. The overall behaviour of these two figures may be discussed by observing the thermal and viscous boundary layers. As we know that when the temperature on the surface is relatively high, the fluids inside the boundary layer accelerate.
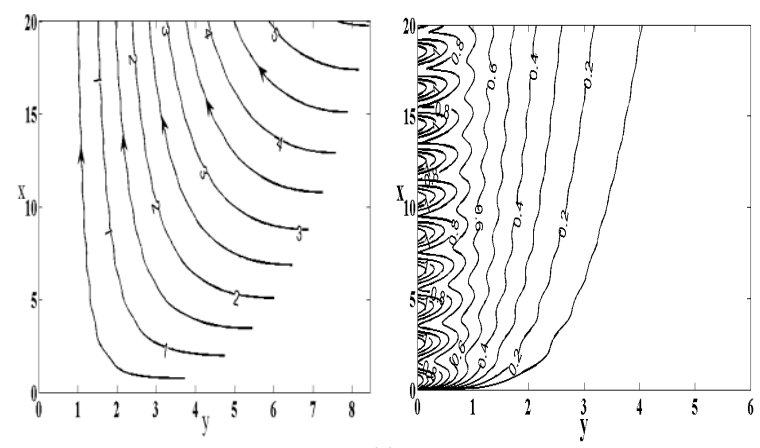

(a)
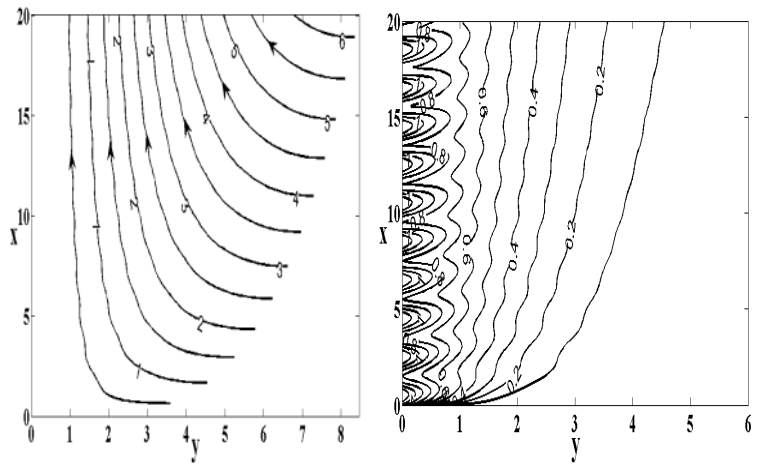

(b)
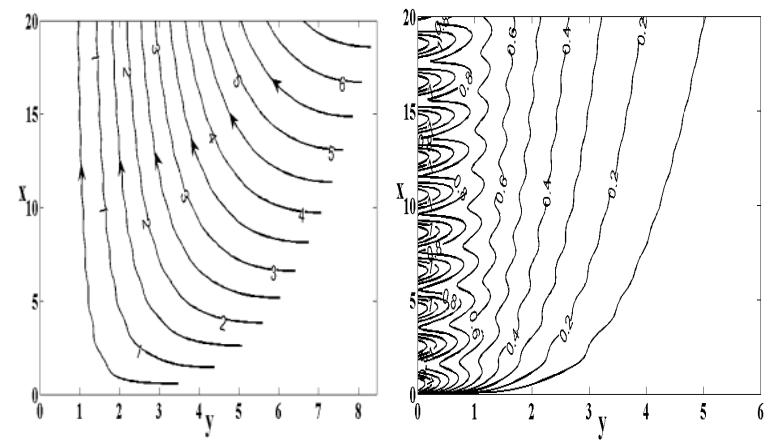

(c)

Fig. 5. Streamlines and Isotherms plot at different nanofluids temp. (a) $300 \mathrm{~K}$ (b) $310 \mathrm{~K}$ (c) $320 \mathrm{~K}$ while $\phi=0.04, \alpha=0.2$.

On the other hand, if the surface temperature is low the fluids in the boundary layer have the minimum velocity. Therefore, it is expected that the shear stress and the rate of heat transfer will be higher at the position where the temperature is maximum. As a result the overall heat transfer will be from the fluid into the surface which can be clearly seen in Fig. 4(b) where the Nusselt number is shown as negative. The nanofluid has comparatively high skin friction and Nusselt number because of high thermal conductivity and viscosity of nanofluids as shown in Fig. 3.

Fig. 5 shows the streamlines and temperature contours for different temperatures in nanofluids with $4 \%$ nanoparticle concentration. It is seen that the streamlines concentrate near the wall as we go for higher temperature. Due to consequences of that the skin friction coefficient is higher for high temperature as shown in Fig. 7a. On the other hand the thermal boundary layer becomes thicker as the temperature increases. The flow of the nanofluid appears to be oscillating near the surface of the plate due to streamwise variations of the surface temperature.
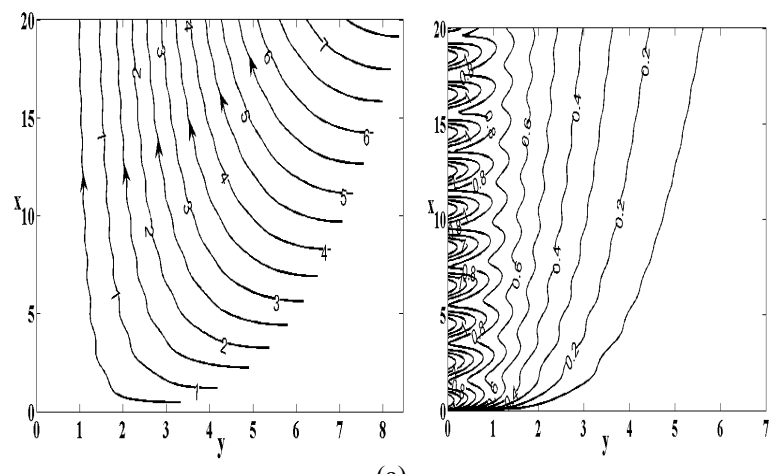

(a)
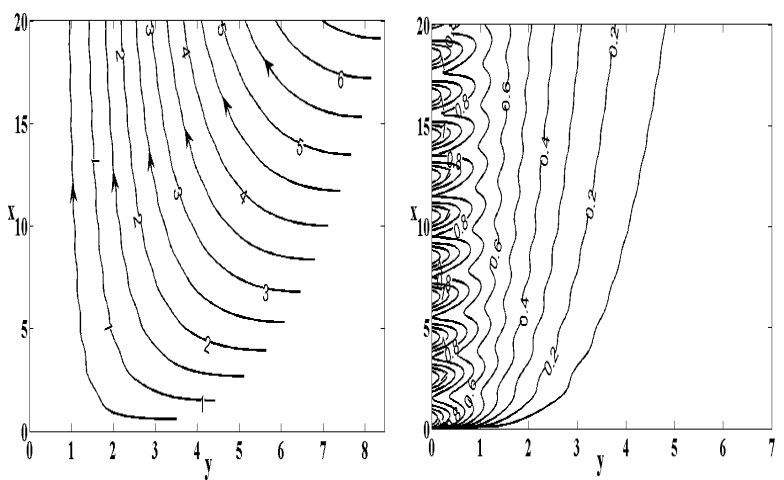

(b)

Fig. 6. Streamlines and Isotherms plot for different nanoparticle diameter (a) $20 \mathrm{~nm}$ (b) $50 \mathrm{~nm}$ while $\phi=0.04, \alpha=0.2$. 
The effect of nanoparticle diameter has been shown in figs. 6 (a-b). The streamlines and temperature contours for two different nanoparticle diameter, $\mathrm{d}=20 \mathrm{~nm}$ and $\mathrm{d}=50 \mathrm{~nm}$ has been plotted. Comparatively, we found that streamline concentration and thickness of temperature contours is higher for small size nanoparticle. It can be explained on the basis of higher Brownian motion of small size nanoparticle which leads to increase the dynamic thermal conductivity.

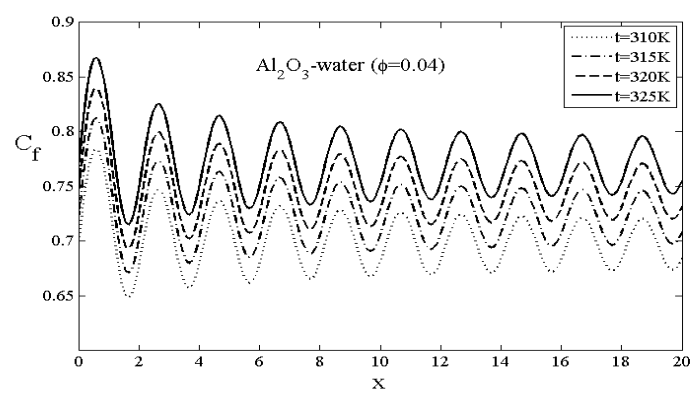

(a)

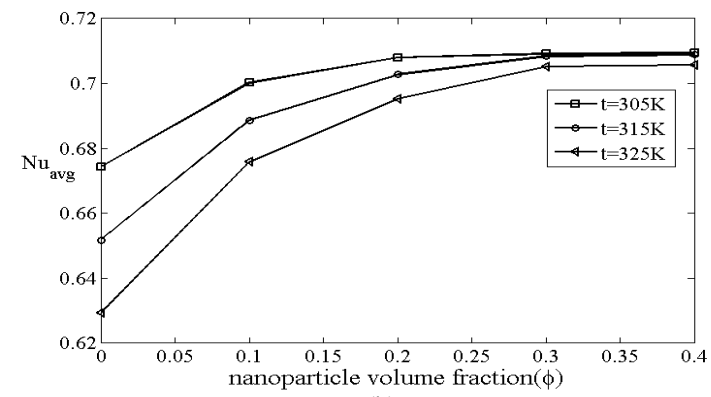

(b)

Fig. 7. (a) skin friction coefficient for different temperatures (b) Average Nusselt number with volume fraction for different temperatures.

The effect of nanoparticle volume fraction $(\phi)$ on average Nusselt number has been calculated for different temperatures in Fig. 7b. It is found that heat transfer increases nonlinearly with the increase with nanoparticles from 0 to $4 \%$. It can easily be noted that this effect is almost constant from 3 to $4 \%$. It is due to that higher concentration of nanoparticles lead to sedimentation. Moreover, the heat transfer is decreased with increase in temperature.

TABLE I: GRID INDEPENDENCE STUDY FOR A NANOFLUID WITH $\phi=0.04$,

\begin{tabular}{cccc}
\multicolumn{3}{c}{$\alpha=0.2, t=325 \mathrm{~K}$} \\
\hline \hline Grid Size & Pure water & $\begin{array}{c}\mathrm{Al}_{2} \mathrm{O}_{3} \text {-water } \\
(\text { nanoparticle size } \\
\mathrm{d}=20 \mathrm{~nm})\end{array}$ & $\begin{array}{c}\mathrm{Al}_{2} \mathrm{O}_{3} \text {-water } \\
\text { (nanoparticle size } \\
\mathrm{d}=100 \mathrm{~nm})\end{array}$ \\
\hline \hline $61 \times 21$ & 0.585722 & 1.047726 & 0.797934 \\
$61 \times 41$ & 0.584432 & 1.043817 & 0.796224 \\
$81 \times 61$ & 0.583936 & 1.042091 & 0.795654 \\
$101 \times 61$ & 0.582925 & 1.041786 & 0.795015 \\
$141 \times 81$ & 0.582736 & 1.040617 & 0.794792 \\
$181 \times 101$ & 0.582663 & 1.040591 & 0.794612 \\
$201 \times 121$ & 0.582636 & 1.040571 & 0.794602 \\
\hline \hline
\end{tabular}

\section{CONCLUSION}

Here we have investigated the steady two-dimensional natural convection laminar flow of viscous incompressible $\mathrm{Al}_{2} \mathrm{O}_{3}$-water nanofluid along a vertical flat plate with streamwise surface temperature. Effects of various physical parameters arise from the governing equations and the boundary conditions on fluid flow and heat transfer have been shown. The outcomes of the results can be summarised as follows:

* Both skin-friction and Nusselt number are enhanced considerably, owing to increase in the values of the nanoparticle volume fraction,

* With the increase of the amplitude of the heating effect both skin friction and Nusselt number also increase. The effect is more pronounced with the use of nanofluids.

* Viscous and thermal boundary layers increase with the increase of ambient temperature. It is due to the increase in dynamic thermal conductivity of nanofluid with temperature.

* Different nanoparticle size can also be used to control the motion and temperature of fluid. Small sized nanoparticle has found to be high Nusselt number as compared to large sized.

\section{ACKNOWLEDGMENT}

P.R Author would like to thank Council of Scientific and Industrial Research (CSIR), Government of India, for its financial support through the award of a research grant.

\section{REFERENCES}

[1] S. U. S. Choi, "Enhancing thermal conductivity of fluids with nanoparticles in developments and applications of non-Newtonian flows," ASME, FED-vol. 231/MD-vol. 66, pp. 99-105, 1995.

[2] J. A. Eastman, S. U. S. Choi, S. Li, W. Yu, and L. J. Thompson, "Anomalously increased effective thermal conductivities of ethylene glycol-based nanofluids containing copper nanoparticles," Applied Physics Letter, vol. 78, pp. 718-720, 2001.

[3] X. Wang, X. Xu, and S. U. S. Choi, "Thermal conductivity of nanoparticle-fluid mixture, Journal of Thermophysics Heat Transfer, vol. 13, pp. 474-480, 1999.

[4] Y. Xuan and Q. Li, "Heat Transfer Enhancement of Nanofluids," International Journal of Heat Fluid Flow, vol.1, pp. 58-64, 2000.

[5] J. Koo and C. Kleinstreuer. "A new thermal conductivity model for nanofluids," Journal of Nanoparticle Research, vol.6, pp. 577-588, 2004.

[6] S. Ostrach, "An analysis of laminar free convection flow and heat transfer about a flat plate parallel to the direction of the generating body force," NACA, TN 2635, 1952.

[7] E. M. Sparrow, and J. L. Gregg, "Similar solution for free convection from a non-isothermal vertical plate," Trans. ASME J. Heat Transfer, vol. 80 , pp. 379-384, 1958.

[8] D. A. S. Rees, "The effect of steady streamwise surface temperature variations on vertical free convection," Int. J. Heat Mass Transfer, vol. 31, pp. 1344-1353, 1999.

[9] N. C. Roy, and M. A. Hossain, "Numerical solution of a steady natural convection flow from a vertical plate with the combined effects of streamwise temperature and species concentration variations," Heat Mass Transfer, vol.46, pp. 509-522, 2010.

[10] S. C. Saha, J. C. Patterson, and C. Lei, "Natural convection and heat transfer in attics subject to periodic thermal forcing," Int. J. Thermal Sci. vol. 49, pp. 1899-1910, 2010.

[11] M. M. Molla, S. C. Saha, and M. A. Hossain, "Radiation effect on free convection laminar flow along a vertical flat plate with streamwise sinusoidal surface temperature," Mathematical and Computer Modelling, vol.53, pp. 1310-1319, 2011.

[12] J. Li, Computational analysis of nanofluid flow in microchannels with applications to micro-heat sinks and bio-MEMS, Ph.D. dissertation, MAE department, NCSU, Raleigh, NC, 2008.

[13] F. P. Incropera and D. P. Dewitt, Fundamentals of Heat and Mass Transfer, John Wiley \& Sons, 2002. 
[14] P. Rana and R. Bhargava, "Numerical study of heat transfer enhancement in mixed convection flow along a vertical plate with heat source/sink utilizing nanofluids," Communications of Nonlinear Sciences and Numerical Simulation, vol.16, pp. 4318-4334, 2011.

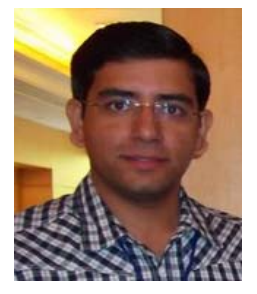

Puneet Rana, born on 11-11-1986 in Ludhiana, Punjab, India, is a Research Scholar of Department of Mathematics, Indian Institute of Technology Roorkee, India. He did his B.Sc. from S.C.D. Govt College, Ludhiana, Punjab, India in 2006 and M.Sc. (Hons.) in Mathematics from Panjab University Campus, Chandigarh, Punjab, India in 2008. He is pursuing his Ph. D. under the supervision of Prof Rama Bhargava, since 2009 and published research papers in International Journals and Conferences on heat transfer characteristics of Micro and nanofluids. He awarded National Merit Scholarship in his graduation. He has also awarded with CSIR fellowship in 2008. He cleared GATE during his Masters of Science program. His research interest includes Micropolar fluids, Nanofluids, Heat transfer and Finite Element method.

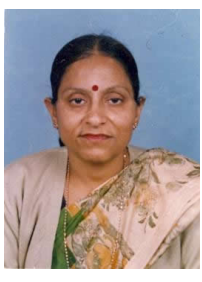

Rama Bhargava, born on 01-09-1955, is presently holding the post of Professor \& Head, Department of Mathematics, Indian Institute of Technology, Roorkee, India. She did her B.Sc. degree from Meerut University, UP, India in 1973, M.Sc. and Ph.D. in Mathematics from IIT, Roorkee, India in 1975 and 1978 respectively. Her about 100 research articles in various International Journals and Conferences were published. She has more than 32 years of teaching and research experience. She has already guided 7 students for Ph.D. and 57 students for PG projects/ dissertations. Her research interest includes Computational Fluid Dynamics, FEM, Meshfree techniques, Computer Graphics and Bio-Mathematics. She won various National and International awards including Australian endeavour executive award, INSA exchange award etc. She has also the life memberships of various societies viz. Indian Mathematical Society, Indian Society of Theoretical and Applied Mathematics, Society for Mathematical Modelling and Computer Simulation etc. 